\title{
Evaluating inhaler use technique in COPD patients
}

This article was published in the following Dove Press journal:

International Journal of COPD

8 July 2015

Number of times this article has been viewed

\section{Chaicharn Pothirat \\ Warawut Chaiwong \\ Nittaya Phetsuk \\ Sangnual Pisalthanapuna \\ Nonglak Chetsadaphan \\ Woranoot Choomuang}

Division of Pulmonary, Critical Care and Allergy, Department of Internal Medicine, Faculty of Medicine, Chiang Mai University, Chiang Mai, Thailand
Correspondence: Chaicharn Pothirat Division of Pulmonary, Critical Care and Allergy, Department of Internal Medicine, Faculty of Medicine, Chiang Mai University, I I0 Inthavaroros Rd, Sriphum, Maung Chiang Mai District, Chiang Mai, 50200 Thailand

$\mathrm{Tel}+6653946228$

Fax +66 53895117

Email cpothira@med.cmu.ac.th
Background: Poor inhalation techniques are associated with decreased medication delivery and poor disease control in chronic obstructive pulmonary disease (COPD). The purpose of this study was to evaluate techniques for using inhaler devices in COPD patients.

Methods: A prospective cross-sectional study was conducted to assess patient compliance with correct techniques for using inhaler devices across four regimens, ie, the pressurized metered-dose inhaler (pMDI), the pMDI with a spacer, the Accuhaler ${ }^{\circledR}$, and the Handihaler ${ }^{\circledR}$. The percentage of compliance with essential steps of correct device usage for each regimen was recorded without prior notification when COPD patients presented for a routine visit, and 1 month after receiving face-to-face training. We compared the percentage of compliance between the devices and risk factors related to incorrect techniques using logistic regression analysis. Percentage of patient compliance with correct techniques was compared between the two visits using the chi-square test. Statistical significance was set at $P<0.05$.

Results: A total of 103 COPD patients (mean age 71.2 \pm 9.2 years, males $64.1 \%$, low education level $82.5 \%$, and percent predicted forced expiratory volume in 1 second $51.9 \pm 22.5$ ) were evaluated. Seventy-seven patients $(74.8 \%)$ performed at least one step incorrectly. Patients using the Handihaler had the lowest compliance failure (42.5\%), and the odds ratio for failure with the other devices compared with the Handihaler were 4.6 (95\% confidence interval [CI] 1.8-11.8) for the pMDI, 3.1 (95\% CI 1.2-8.2) for the pMDI with a spacer, and 2.4 (95\% CI 1.1-5.2) for the Accuhaler. Low education level was the single most important factor related to incorrect technique (adjusted odds ratio 4.1, 95\% CI 1.2-13.4, $P=0.022$ ). Formal training resulted in a statistically significant decrease in percentage of incorrect techniques for all devices and for the pMDI $(59.4 \%$ vs $48.6 \%, P<0.001 ; 72.4 \%$ vs $48.3 \%$, $P=0.039$, respectively).

Conclusion: Inhalation technique in COPD patients without face-to-face training was mostly unsatisfactory, especially in patients with low education levels. The Handihaler was the inhaler device associated with the lowest technique failure. Face-to-face inhalation technique training significantly increased technique compliance for the pMDI.

Keywords: chronic obstructive pulmonary disease, inhalation, technique, compliance

\section{Introduction}

Inhaler devices are a mainstay in the management of chronic obstructive pulmonary disease (COPD), and their proper usage requires continuous training. ${ }^{1,2}$ Device selection should be based on availability, cost, patient and physician preference, and clinical setting.,4 Many inhaler devices have been developed, and each has specific instructions for usage to ensure suitable drug dose delivery to the airways. Although a number of different devices have enabled technological improvements in airway drug delivery, important limitations still remain. ${ }^{5}$ Poor inhalation techniques are associated with decreased medication delivery and poor disease control. ${ }^{6}$

The correct use of inhaler devices is one of the most important aspects to be taken into account when evaluating the progress of disease treatment among individuals with 
COPD, and guidelines emphasize the importance of assessing inhalation technique to improve the efficiency of drug delivery. ${ }^{1}$ Errors in the use of such inhaler devices have also been reported in earlier studies. ${ }^{7,8}$ In several previous studies, incorrect technique was reported in up to $94 \%$ of patients. ${ }^{9-14}$ Patient-related determinants such as sex, ${ }^{15}$ age, ${ }^{14,16-19}$ education level, ${ }^{14}$ and severity of obstruction ${ }^{14,17}$ were associated with incorrect technique. The type of inhaler device is also an important determinant of incorrect technique. ${ }^{14,20,21}$

Therefore, it is necessary on the part of the physicians, nurses, and other health care providers, to understand the issues related to performance and correct use of these inhaler devices, and also to understand the difficulties faced by patients while using them. In Thailand, lack of data in this regard makes the situation more difficult to address. The objective of this study was to evaluate and analyze inhalation techniques in COPD patients using common devices.

\section{Materials and methods}

A prospective cross-sectional study was conducted in the outpatient chest clinic at Chiang Mai University Hospital, Chiang Mai, Thailand, from March 2013 to February 2014. We assessed the commonly used controller devices available in Thailand, ie, the pressurized metered-dose inhaler (pMDI), the pMDI with a volumatic spacer, the Accuhaler ${ }^{\circledR}$, and the Handihaler ${ }^{\circledR}$. Stable COPD patients previously diagnosed in accordance with the Global Initiative for Chronic Obstructive Lung Disease (GOLD) criteria ${ }^{1}$ and who had been using one of the four types of inhaler devices longer than 3 months prior to the study were screened for enrollment. Inclusion criteria also included: COPD patients who received verbal instructions on the correct inhalation techniques for their particular inhaler device for more than 3 months only from their pharmacists. Exclusion criteria included: use of other kinds of inhaler devices; receiving a face-to-face training program on inhalation technique from our COPD clinic; and acute exacerbation or hospitalization within the previous 6 weeks. Enrolled patients were assessed for inhalation technique compliance at their routine medical (pre-training) visits by a qualified respiratory nurse without prior notification. This assessment was performed in an infirmary room before the meeting with a physician. The use of each inhaler device was evaluated in a practical manner by asking patients to demonstrate their inhalation technique using their prescribed devices containing placebo medications. They were asked to say each step as they were performing it, so that all of the steps could be clearly observed. We developed a checklist measuring essential steps required for adequate drug delivery for each device based on the instructions provided by the manufacturer and from previous studies. ${ }^{14,22}$ The number of required steps varied from five to seven. When one or more errors were made regarding these essential steps, we considered it unlikely that a significant amount of medicine would be inhaled. In these cases, inhalation technique was defined as incorrect. The respiratory nurse observed each step of the inhalation technique and recorded each incorrect step. After the assessment, patients were given instructions, face-to-face demonstrations regarding the correct use of the controller devices, and training until they could use the devices correctly. One month later (post-training visit), all patients were requested to demonstrate their inhalation techniques and were reevaluated by the same nurse.

All subjects underwent spirometry in accordance with the guidelines of the American Thoracic Society and the European Respiratory Society ${ }^{23}$ for measuring forced expiratory volume in 1 second $\left(\mathrm{FEV}_{1}\right)$, forced vital capacity, and ratio of $\mathrm{FEV}_{1}$ to forced vital capacity unless their medical records contained documented results of spirometry within the past 6 months. The Thai version of the COPD Assessment Test (CAT), ${ }^{24}$ was administered to all subjects at the enrollment visit, and their modified Medical Research Council ${ }^{25}$ dyspnea scores were recorded. The numbers and types of inhaler controller devices were also recorded. Any exacerbation within the previous year was also noted. Exacerbation was defined as a worsening of two or more major symptoms for 2 or more consecutive days as determined by a physician (dyspnea, sputum volume, sputum purulence), and requiring treatment with either systemic corticosteroids or antibiotics, or combinations of the two as necessary. ${ }^{1}$

Patients were evaluated for potential factors associated with incorrect inhalation technique including age, sex, severity of disease classified by GOLD, dyspnea assessed by modified Medical Research Council score, quality of life assessed by CAT questionnaire, level of education (primary school, secondary school, or higher), use of multiple devices, and whether treatment by a pulmonologist had been provided in the previous 2 years. This study was approved by the research ethics committee at the Faculty of Medicine, Chiang Mai University. A written informed consent was obtained from each patient before the study.

\section{Statistical analysis}

Data are presented as the mean \pm standard deviation unless stated otherwise. Handling errors per device were defined as the percentage of subjects who incorrectly performed each step. The relationship between type of device and 
incorrect inhalation technique was analyzed using multivariable logistic regression. The potential risk factors for an incorrect inhalation technique from univariable logistic regression analysis with a $P$-value $<0.25$ were further analyzed using logistic multivariable analysis. ${ }^{26}$ The results are displayed as odds ratios together with $95 \%$ confidence intervals. Comparison percentages of incorrect inhalation technique between pre-training and post-training visits within groups were analyzed using the chi-square test. Statistical significance was accepted at $P<0.05$. All analyses were carried out using Statistical Package for the Social Sciences version 16 software for Windows (SPSS Inc, Chicago, IL, USA).

\section{Results}

A total of 103 COPD patients performing a total of 200 inhalation demonstrations were included in the study. Patient demographics and clinical characteristics are presented in Table 1 . The patients were elderly (mean age $71.2 \pm 9.2$ years), predominantly male $(64.1 \%)$, with moderate-tosevere $\operatorname{COPD}\left(51.9 \% \pm 22.5 \%\right.$ predicted $\left.\mathrm{FEV}_{1}\right)$, and approximately $70 \%$ were using multiple types of inhaler devices. Most of them had a low education level (primary school), and slightly more than half of them have been receiving treatment by a pulmonologist at our chest clinic in the past 2 years.

Accuhaler users ( $\mathrm{n}=83,41.5 \%)$ were the highest among the enrolled population followed by pMDI users ( $\mathrm{n}=44,22.0 \%)$,
Handihaler users ( $\mathrm{n}=40,20.0 \%)$, and $\mathrm{pMDI}$ with spacer users $(n=33,16.5 \%)$. Seventy-seven patients $(74.8 \%)$ performed at least one essential step incorrectly for all devices. A total of 200 inhalation demonstrations from the 103 patients were used for the analysis per device. Percentages of incorrect essential steps and multivariable analysis of performing incorrect technique per device are presented in Table 2. The maximum number of technique errors was observed in those using the pMDI (77.3\%), and the minimum number of errors in those using the Handihaler (42.5\%). For the pMDI, the steps "breathe out gently to residual volume" and "shake inhaler thoroughly" were most frequently performed incorrectly. For the pMDI with spacer, the step "breathe in and out through mouthpiece at least three times" was most frequently performed incorrectly. For the Accuhaler, the steps "breathe out gently to residual volume" and "inhale forcefully and deeply" were most frequently performed incorrectly. For the Handihaler, the step "hold breath for at least 10 seconds" was most frequently performed incorrectly. Multivariable analysis (Handihaler device set as a reference group due to the lowest incorrect steps of inhalation) revealed significant differences in incorrect inhalation techniques between the devices, as demonstrated by the odds ratios presented in Table 2.

Univariable analysis of determinants revealed three potential risk factors for incorrect inhalation technique: low education level (education $\leq 6$ years); age $\geq 70$ years; and CAT score $\geq 10$ (Table 3 ). No associations could be observed

Table I Demographic and clinical characteristics of COPD patients

\begin{tabular}{|c|c|c|}
\hline Characteristics & $n=103$ & \\
\hline Age (years) & $71.2 \pm 9.2$ & \\
\hline Male sex, n (\%) & $66(64.1)$ & \\
\hline Body mass index $\left(\mathrm{kg} / \mathrm{m}^{2}\right)$ & $20.7 \pm 3.9$ & \\
\hline \multicolumn{3}{|l|}{ Education level } \\
\hline Lower education ( $\leq 6$ years) & $85(82.5)$ & \\
\hline Higher education ( $>6$ years) & $18(17.5)$ & \\
\hline Percent predicted FEV, & $51.9 \pm 22.5$ & \\
\hline Ratio of FEV,/FVC (\%) & $54.1 \pm 12.2$ & \\
\hline \multirow[t]{5}{*}{ GOLD } & Classification & Stage $^{a}$ \\
\hline & A $28(27.2)$ & $19(8.8)$ \\
\hline & В $20(19.4)$ & II 40 (39.2) \\
\hline & C I7 (16.5) & III $39(38.2)$ \\
\hline & D 38 (36.9) & IV I4 (13.7) \\
\hline mMRC score & $2.0 \pm 1.1$ & \\
\hline CAT score & $10.6 \pm 6.7$ & \\
\hline Frequent $A E s$ in the previous year ( $\geq 2$ times per year) & $23(22.3)$ & \\
\hline AEs in the previous year $(n)$ & $1.0 \pm 1.9$ & \\
\hline Treatment by a pulmonologist in previous 2 years & $57(55.3)$ & \\
\hline Multiple devices ( $\geq 2$ devices) & $72(69.9)$ & \\
\hline
\end{tabular}

Note: Data are shown as the $\mathrm{n}(\%)$ or as the mean \pm standard deviation, ${ }^{\mathrm{a}} \mathrm{n}=102$.

Abbreviations: COPD, chronic obstructive pulmonary disease; FEV , forced expiratory volume in I second; FVC, forced vital capacity; mMRC, modified Medical Research Council; CAT, COPD Assessment Test; GOLD, Global Initiative for Chronic Obstructive Lung Disease; AE, acute exacerbation. 
Table 2 Percentages of mistakes per step, total percentages of patients with incorrect inhalation technique per controller device, and multivariate analysis per device

\begin{tabular}{|c|c|c|c|c|}
\hline Essential steps & $\begin{array}{l}\text { pMDI } \\
n=44\end{array}$ & $\begin{array}{l}\text { pMDI + } \\
\text { spacer, n=33 }\end{array}$ & $\begin{array}{l}\text { Accuhaler }^{\circledR} \\
\mathrm{n}=83\end{array}$ & $\begin{array}{l}\text { Handihaler }^{\circledR} \\
\mathrm{n}=\mathbf{4 0}\end{array}$ \\
\hline Shake inhaler thoroughly & 52.3 & 39.4 & NA & NA \\
\hline Remove the cap and keep inhaler in upright position & $\mathrm{II} .4$ & NA & NA & NA \\
\hline Slide the outer case away until it clicks & NA & NA & 4.8 & NA \\
\hline Slide the lever away until it clicks & NA & NA & 8.4 & NA \\
\hline Remove cap and insert inhaler correctly into spacer & NA & 12.1 & NA & NA \\
\hline Place capsule in the device and turn back mouthpiece & NA & NA & NA & 4.9 \\
\hline Push the buttons once & NA & NA & NA & 7.3 \\
\hline Breathe out gently to residual volume & 54.5 & 33.3 & 38.8 & 17.1 \\
\hline Close lips on inhaler or spacer mouthpiece & 0.0 & 0.0 & 0.0 & 0.0 \\
\hline Press the canister at beginning of inhalation & 40.9 & NA & NA & NA \\
\hline Hold spacer level and press down firmly on canister once & NA & 21.2 & NA & NA \\
\hline Inhale slowly and deeply & 27.3 & 30.3 & NA & NA \\
\hline Inhale forcefully and deeply & NA & NA & 36.1 & 14.6 \\
\hline Hold breath for at least 10 seconds & 38.6 & 24.2 & 30.1 & 24.4 \\
\hline Breathe in and out through mouthpiece at least three times & NA & 42.4 & NA & NA \\
\hline Patients performing incorrect inhalation techniques & 77.3 & 69.7 & 63.9 & 42.5 \\
\hline Odds ratio & 4.6 & 3.1 & 2.4 & 1.0 \\
\hline $95 \%$ confidence interval & $1.8-11.8$ & $1.2-8.2$ & $1.1-5.2$ & \\
\hline$P$-value & 0.001 & 0.020 & 0.025 & \\
\hline
\end{tabular}

Abbreviations: pMDI, pressurized meter-dose inhaler; NA, not applicable to the device.

regarding severity of disease, frequency of exacerbation, treatment by a pulmonologist in the previous 2 years, or use of multiple devices. Multivariable logistic regression revealed that a low education level was the only explanatory factor for incorrect inhalation technique (adjusted odds ratio 4.1, 95\% confidence interval 1.2-13.4, $P=0.022$, Table 4).
At the post-training visit, $67 \%$ of patients $(69 / 103)$ performed a total of 138 inhaler device demonstrations and their inhalation techniques were assessed again. Comparisons of incorrect techniques before and after face-to-face training visits are shown in Figure 1. Formal training resulted in a statistically significant decrease in the percentage of

Table 3 Risk factors for incorrect inhalation techniques by univariable analysis $(n=103)$

\begin{tabular}{|c|c|c|c|c|c|}
\hline Variables & & $\mathbf{n}$ & Incorrect (\%) & $\begin{array}{l}\text { Crude OR } \\
(95 \% \mathrm{Cl})\end{array}$ & $P$-value \\
\hline \multirow[t]{2}{*}{ Sex } & Female & 37 & 83.8 & $2.2(0.8-6.2)$ & 0.114 \\
\hline & Male (Ref) & 66 & 69.7 & & \\
\hline \multirow[t]{2}{*}{ Age } & $\geq 70$ years & 58 & 81.0 & $2.1(0.9-5.3)$ & 0.096 \\
\hline & $<0$ years (Ref) & 45 & 66.7 & & \\
\hline \multirow[t]{2}{*}{ Education } & Low ( $\leq 6$ years) & 85 & 80.0 & $4.0(1.4-11.6)$ & 0.008 \\
\hline & High $(>6$ years) (Ref) & 18 & 50.0 & & \\
\hline \multirow[t]{2}{*}{ Percent predicted of $\mathrm{FEV}_{1}{ }^{a}$} & $<50$ & 53 & 77.4 & I.4 (0.5-3.3) & 0.492 \\
\hline & $\geq 50$ years $($ Ref) & 49 & 71.4 & & \\
\hline \multirow[t]{2}{*}{$\mathrm{mMRC}$ score $^{\mathrm{b}}$} & $\geq 2$ & 67 & 77.6 & $1.6(0.7-4.2)$ & 0.279 \\
\hline & $<2$ (Ref) & 34 & 67.6 & & \\
\hline \multirow[t]{2}{*}{ CAT score ${ }^{b}$} & $\geq 10$ & 54 & 81.5 & $2.3(0.9-5.7)$ & 0.075 \\
\hline & $<10$ (Ref) & 47 & 66.0 & & \\
\hline Frequent $\mathrm{AE}$ in the previous year & Yes & 23 & 73.9 & $0.9(0.3-2.7)$ & 0.916 \\
\hline$(\geq 2$ times/year) & No (Ref) & 80 & 75.0 & & \\
\hline Treatment by a pulmonologist & Yes & 46 & 76.1 & I.I (0.5-2.8) & 0.780 \\
\hline in the previous 2 years & No (Ref) & 57 & 73.7 & & \\
\hline \multirow[t]{2}{*}{ Inhaler device } & Multiple & 72 & 77.8 & I.7 (0.6-4.2) & 0.282 \\
\hline & Single (Ref) & 31 & 67.7 & & \\
\hline
\end{tabular}

Note: Data are shown as $\mathrm{n}(\%)$ or the mean \pm standard deviation, ${ }^{\mathrm{a}} \mathrm{n}=102,{ }^{\mathrm{b}} \mathrm{n}=101$.

Abbreviations: $\mathrm{Cl}$, confidence interval; COPD, chronic obstructive pulmonary disease; $\mathrm{FEV}_{1}$, forced expiratory volume in I second; mMRC, modified Medical Research Council; CAT, COPD Assessment Test; AE, acute exacerbation; OR, odds ratio; ref, reference. 
Table 4 Risk factors for incorrect inhalation techniques by multivariable analysis $(n=103)$

\begin{tabular}{|c|c|c|c|}
\hline \multicolumn{2}{|l|}{ Variables } & \multirow{2}{*}{$\begin{array}{l}\text { Adjusted OR } \\
(95 \% \mathrm{Cl})\end{array}$} & \multirow{2}{*}{$\begin{array}{l}P \text {-value } \\
0.485\end{array}$} \\
\hline Sex & Female & & \\
\hline & Male (Ref) & & \\
\hline \multirow[t]{2}{*}{ Age } & $\geq 70$ years & $1.9(0.8-5.3)$ & 0.166 \\
\hline & $<70$ years (Ref) & & \\
\hline \multirow[t]{2}{*}{ Education } & Low ( $\leq 6$ years) & $4.1(1.2-13.4)$ & 0.022 \\
\hline & High (>6 years) (Ref) & & \\
\hline \multirow[t]{2}{*}{ CAT score ${ }^{a}$} & $\geq 10$ & $2.3(0.8-6.3)$ & 0.107 \\
\hline & $<10$ (Ref) & & \\
\hline
\end{tabular}

Note: Data are shown as $\mathrm{n}(\%)$ or the mean \pm standard deviation, ${ }^{a} \mathrm{n}=10 \mathrm{I}$. Abbreviations: CAT, COPD Assessment Test; $\mathrm{Cl}$, confidence interval; COPD, chronic obstructive pulmonary disease; OR, odds ratio; Ref, reference.

incorrect techniques for all devices and for the pMDI (59.4\% vs $48.6 \%, P<0.001 ; 72.4 \%$ vs $48.3 \%, P=0.039$, respectively) and tended to decrease for the pMDI with spacer and for the Accuhaler. However, incorrect inhalation techniques in patients using the Handihaler did not decrease.

\section{Discussion}

This study shows that a large proportion of COPD patients routinely treated by pulmonologists at the chest clinic used their inhaler incorrectly by performing at least one essential step for drug delivery incorrectly. The most errors were made when using a pMDI, whereas those patients using the Handihaler device had the highest rate of accurate techniques. The pMDI is inherently more difficult to use and needs appropriate coordination. Adding a spacer to the pMDI helps to eliminate poor hand-lung coordination. ${ }^{27}$
This is consistent with our study results. The most frequent error in handling the pMDI was the step "press the canister at beginning of inhalation". The group of patients using the pMDI with a spacer also demonstrated high incorrect technique performance at this step. These high rates of poor hand-lung coordination for the two devices could be the result of inadequate routine technique education provided by pharmacists and poor patient inhalation technique evaluation by pulmonologists and nurses. Previous studies have revealed that health care providers, including physicians, nurses, pharmacists, and respiratory technicians themselves, may not be acquainted with appropriate device handling. ${ }^{28,29}$

Low education level was the only statistically significant factor associated with incorrectly performing the inhalation technique. Other variables, including older age, female sex, severity of dyspnea and lung function impairment, low CAT score, history of frequent exacerbation, being treated by a pulmonologist in the previous 2 years, and use of multiple devices, were not associated with incorrect technique. An inverse relationship between years of school education and incorrect inhalation technique has been reported previously. ${ }^{30}$ When considering demographic variables in the univariable analysis, we observed a higher odds ratio for incorrect inhalation technique in the elderly, as has been observed in other studies. ${ }^{17,31}$ Our data also suggest that females, when compared with males, present greater odds of having incorrect inhalation technique. However, other published studies reported no differences in inhalation technique related to sex. ${ }^{17,30}$ This is the first study to use the CAT questionnaire for assessment of

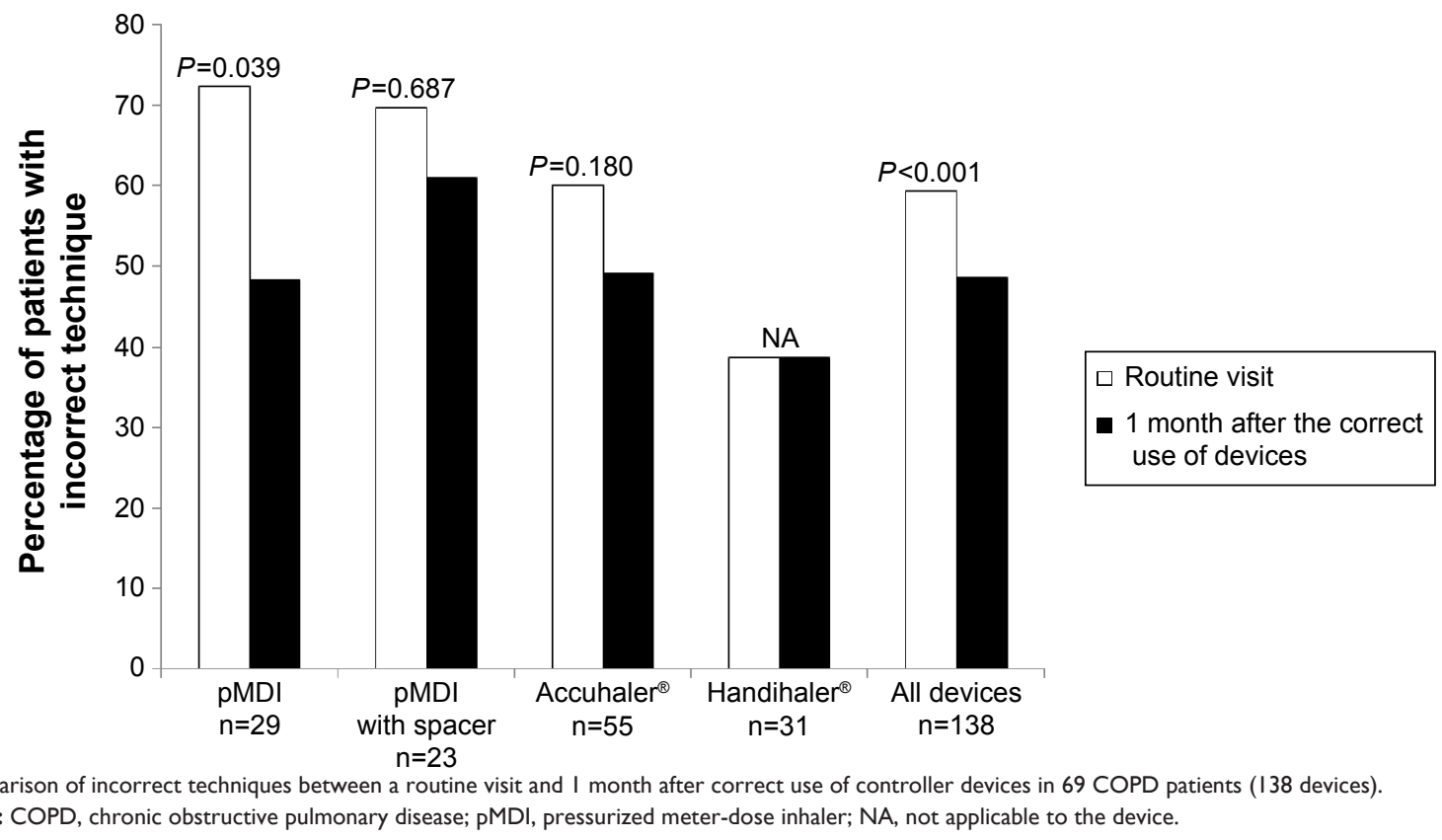

International Journal of COPD 2015:10

submit your manuscript $\mid$ www.dovepress.com 
quality of life. The data suggest that patients with lower quality of life (CAT score $\geq 10$ ) are more likely to have incorrect inhalation technique. A previous study demonstrated that mishandling of inhaler technique remains common in everyday life and is associated with poor clinical control and increased expenditure of unscheduled health care resources in COPD patients. ${ }^{30}$ A previous study reported more technique errors among patients using multiple types of devices, ${ }^{21}$ however, our results are in agreement with a report stating that the number of inhaler types used has no effect on performance of the required inhalation technique. ${ }^{17}$ No other variables (elderly, female sex, poorer quality of life, and use of multiple inhaler devices) were statistically significant in our study.

Our study confirms a significant increase in the percentage of improvement in inhalation technique after face-toface demonstrations and training. Although the inhalation technique significantly improved among pMDI, pMDI with spacer, and Accuhaler patients, the percentage of those with incorrect technique was still above $50 \%$. Surprisingly, patient compliance using the Handihaler did not improve further after demonstration and training.

These results suggest that patients should bring all their inhalers to each visit, and should be able to demonstrate their correct use. All patients need face-to-face training and retraining, while others will require a family member to help them recall training instructions for successful inhaler use. Inhaler technique must be rechecked, and education must be regularly reinforced to maintain correct technique, given that inhaler technique can deteriorate again after education. ${ }^{32,33}$ Handouts or videos, alone or in combination, are not adequate substitutes for face-to-face training, and as previously mentioned, the trainer must be aware of each patient's learning needs. ${ }^{34}$ The basics of effective inhaler training and consequently effective treatment are simplification, demonstration, and repetition. ${ }^{34}$ Regular reassessment and reinforcement of correct inhalation technique is essential for successful inhaler use.

This study has strengths that should be considered. First, it is the first study to compare compliance with inhalation technique for all the frequently prescribed inhaler devices available in Thailand. Second, the same nurse evaluated the same patients for both pre-training and post-training visits to avoid interobserver variability. Third, our study represents a more reliable approach to real-world clinical practice. Bias was further mitigated when COPD patients were assessed without prior notification of the study or researcher knowledge of their inhaler education at their routine visit. None of our study patients had ever been trained using a face-to-face demonstration.
However, this study also has some limitations. First, it evaluated inhalation technique without a quality grading. This method may overestimate the prevalence of incorrect use of inhaler devices, since it considers all steps recommended by manufacturers as a potential source of error, but reduces the subjectivity of grading the relevance of some errors over others in the absence of solid knowledge regarding the importance of each error on the distribution of the drug into the airways. Second, we recognize that evaluating some steps only through observation is subjective, especially the rapid and forceful inhalation step needed to correctly use a dry powder inhaler, but it simulates real-life settings where most decisions are clinically based, and the equipment needed to accurately measure inspiratory flow is seldom available. This might explain the errors observed for the steps of "breathing out gently to residual volume" and "not inhaling forcefully" more commonly with the Accuhaler than for the Handihaler, although these steps are the same for both devices. However, the value of this work rests on the improvement in inhaler use after face-to-face training, confirming the need for repeated education, not only on comparison of inhalation techniques between the devices. Third, this trial was not randomized or controlled, and was conducted in a single health care institution, so we cannot exclude selection bias. This may limit the generalization of our results to other populations. Our institution is an academic chest center, but the inhalation techniques used for common inhaler devices were still largely unsatisfactory. It might be postulated that the correct inhalation technique of COPD patients in general practice clinics is less satisfying without face-to-face training. Fourthly, our study is limited to evaluation of pMDI with large volumatic spacers and not pMDI with small ones.

\section{Conclusion}

Inhalation technique in COPD patients without face-to-face training was mostly unsatisfactory, especially in patients with low education levels. The Handihaler was associated with the highest percentage of correct inhalation technique. Faceto-face training significantly decreased incorrect inhalation techniques in patients using the pMDI.

\section{Acknowledgments}

The authors wish to thank the patients who kindly took part in this study and to acknowledge the staff members of the Division of Pulmonary, Critical Care and Allergy, Department of Internal Medicine, Faculty of Medicine, Chiang Mai University, for their contribution to this trial. 


\section{Author contributions}

C Pothirat developed the study design and carried out acquisition and interpretation of data, statistical analysis, manuscript preparation, and critical revision of intellectual content. The other authors conducted acquisition and interpretation of data, and critical revision of the manuscript. All authors read and approved the final manuscript.

\section{Disclosure}

The authors report no conflicts of interest in this work.

\section{References}

1. Global Strategy for the Diagnosis Management and Prevention of COPD. Global initiative for chronic obstructive lung disease (GOLD) 2014. Available from: http://www.goldcopd.org/. Accessed March 13, 2014.

2. Wright J, Brocklebank D, Ram F. Inhaler devices for the treatment of asthma and chronic obstructive airways disease (COPD). Qual Saf Health Care. 2002;11:376-382.

3. Chapman KR, Voshaar TH, Virchow JC. Inhaler choice in primary practice. Eur Respir Rev. 2005;14:117-122.

4. Virchow JC, Crompton GK, Dal Negro R, et al. Importance of inhaler devices in the management of airway disease. Respir Med. 2008;102 $10-19$.

5. Dolovich MB, Ahrens RC, Hess DR, et al. Device selection and outcomes of aerosol therapy: evidence-based guidelines: American College of Chest Physicians; American College of Asthma, Allergy, and Immunology. Chest. 2005;127:335-371.

6. Cochrane MG, Bala MV, Downs KE, Mauskopf J, Ben-Joseph RH. Inhaled corticosteroids for asthma therapy: patient compliance, devices, and inhalation technique. Chest. 2000;117:542-550.

7. Hesselink AE, Penninx BW, Wijnhoven HA, et al. Determinants of an incorrect inhalation technique in patients with asthma or COPD. Scand J Prim Health Care. 2001;19:255-260.

8. Souza ML, Meneghini AC, Ferraz E, Vianna EO, Borges MC. Knowledge of and technique for using inhalation devices among asthma patients and COPD patients. J Bras Pneumol. 2009;35: 824-831.

9. Brocklebank D, Ram F, Wright J, et al. Comparison of the effectiveness of inhaler devices in asthma and chronic obstructive airways disease: a systematic review of the literature. Health Technol Assess. 2001; 5:1-149.

10. Lavorini F, Magnan A, Dubus JC, et al. Effect of incorrect use of dry powder inhalers on management of patients with asthma and COPD. Respir Med. 2008;102:593-604.

11. Nimmo CJ, Chen DN, Martinusen SM, Ustad TL, Ostrow DN. Assessment of patient acceptance and inhalation technique of a pressurized aerosol inhaler and two breath-actuated devices. Ann Pharmacother. 1993;27:922-927.

12. Arora P, Kumar L, Vohra V, et al. Evaluating the technique of using inhalation device in COPD and bronchial asthma patients. Respir Med. 2014;108:992-998.

13. Ganguly A, Das AK, Roy A, Adhikari A, Banerjee J, Sen S. Study of proper use of inhalational devices by bronchial asthma or COPD patients attending a tertiary care hospital. J Clin Diagn Res. 2014;8:HC04-7.

14. Rootmensen GN, van Keimpema AR, Jansen HM, de Haan RJ. Predictors of incorrect inhalation technique in patients with asthma or COPD: a study using a validated videotaped scoring method. $J$ Aerosol Med Pulm Drug Deliv. 2010;23:323-328.
15. Goodman DE, Israel E, Rosenberg M, Johnston R, Weiss ST, Drazen JM. The influence of age, diagnosis, and gender on proper use of metered-dose inhalers. Am J Respir Crit Care Med. 1994;150 Pt 1: $1256-1261$.

16. van Beerendonk I, Mesters I, Mudde AN, Tan TD. Assessment of the inhalation technique in outpatients with asthma or chronic obstructive pulmonary disease using a metered-dose inhaler or dry powder device. J Asthma. 1998;35:273-279.

17. Wieshammer S, Dreyhaupt J. Dry powder inhalers: which factors determine the frequency of handling errors? Respiration. 2008;75:18-25.

18. Diggory P, Fernandez C, Humphrey A, Jones V, Murphy M. Comparison of elderly people's technique in using two dry powder inhalers to deliver zanamivir: randomized controlled trial. BMJ. 2001;322:577-579.

19. Jarvis S, Ind PW, Shiner RJ. Inhaled therapy in elderly COPD patients; time for re-evaluation? Age Ageing. 2007;36:213-218.

20. Harvey J, Williams JG. Randomised cross-over comparison of five inhaler systems for bronchodilator therapy. Br J Clin Pract. 1992;46: 249-251.

21. van der Palen J, Klein JJ, Kerkhoff AH, van Herwaarden CL. Evaluation of the effectiveness of four different inhalers in patients with chronic obstructive pulmonary disease. Thorax. 1995;50:1183-1187.

22. Lenney J, Innes JA, Crompton GK. Inappropriate inhaler use: assessment of use and patient preference of seven inhalation devices. EDICI. Respir Med. 2000;94:496-500.

23. Miller MR, Hankinson J, Brusasco V, et al. ATS/ERS task force: standardization of lung function test. Eur Respir J. 2005;26:319-338.

24. Pothirat C, Kiatboonsri S, Chuchottaworn C. Validation of the new COPD assessment test translated into Thai in patients with chronic obstructive pulmonary disease. BMC Pulm Med. 2014;14:193.

25. Bestall JC, Paul EA, Garrod R, Garnham R, Jones PW, Wedzicha JA. Usefulness of the Medical Research Council (MRC) dyspnoea scale as a measure of disability in patients with chronic obstructive pulmonary disease. Thorax. 1999;54:581-586.

26. Hosmer D, Lemeshow S. Applied Logistic Regression. 2nd ed. New York, NY, USA: John Wiley \& Sons; 2000.

27. Hindle M, Chrystyn H. Relative bioavailability of salbutamol to the lung following inhalation using metered dose inhalation methods and spacer devices. Thorax. 1994;49:549-453.

28. Hanania NA, Wittman R, Kesten S, Chapman KR. Medical personnel's knowledge of and ability to use inhaling devices. Metered-dose inhalers, spacing chambers, and breath-actuated dry powder inhalers. Chest. 1994;105:111-116.

29. Plaza V, Sanchis J. Medical personnel and patient skill in the use of metered dose inhalers: a multicentric study. CESEA Group. Respiration. 1998;65:195-198.

30. Melani AS, Bonavia M, Cilenti V, et al. Inhaler mishandling remains common in real life and is associated with reduced disease control. Respir Med. 2011;105:930-938.

31. Melani AS, Zanchetta D, Barbato N, et al. Inhalation technique and variables associated with misuse of conventional metered-dose inhalers and newer dry powder inhalers in experienced adults. Ann Allergy Asthma Immunol. 2004;93:439-446.

32. Steier J, Trammer T, Cloes RM, Petro W. Optical feedback training of inhalation with Autohaler and Turbuhaler in COPD patients. Lung. 2003;181:183-192.

33. Crompton GK, Barnes PJ, Broeders M, et al. The need to improve inhalation technique in Europe: a report from the Aerosol Drug Management Improvement Team. Respir Med. 2006;100:1479-1494.

34. Broeders ME, Sanchis J, Levy ML, Crompton GK, Dekhuijzen PN. The ADMIT series-issues in inhalation therapy. 2. Improving technique and clinical effectiveness. Prim Care Respir J. 2009;18:76-82. 
International Journal of COPD

Dovepress

\section{Publish your work in this journal}

The International Journal of COPD is an international, peer-reviewed journal of therapeutics and pharmacology focusing on concise rapid reporting of clinical studies and reviews in COPD. Special focus is given to the pathophysiological processes underlying the disease, intervention programs, patient focused education, and self management protocols.

This journal is indexed on PubMed Central, MedLine and CAS. The manuscript management system is completely online and includes a very quick and fair peer-review system, which is all easy to use. Visit http://www.dovepress.com/testimonials.php to read real quotes from published authors.

Submit your manuscript here: http://www.dovepress.com/international-journal-of-chronic-obstructive-pulmonary-disease-journal 